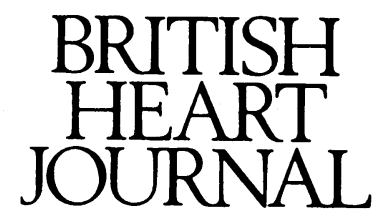

Editorial

\title{
Coronary thrombolysis: round two and beyond
}

Within a remarkably short time of the re-emergence of interest in thrombolytic treatment for acute myocardial infarction the efficacy of this approach was confirmed in several large randomised trials of streptokinase, ${ }^{12}$ anistreplase (anisoylated plasminogen streptokinase activator complex, APSAC), ${ }^{3}$ alteplase (recombinant tissue plasminogen activator), ${ }^{4}$ and streptokinase with adjunctive antiplatelet treatment with aspirin. ${ }^{2}$ Despite their considerable physicochemical and biological differences, treatment with any of these thrombolytic agents is expected to reduce mortality by $25 \%$ to $40 \%$ with added aspirin (at least when added to streptokinase), and the early gains in survival persist for at least 12 months.

These round one single thrombolytic trials have given us reassurance about the relative safety of such treatment in properly selected patients and have indicated what the risks are-a small increased risk of stroke, major bleeding, and allergic reactions (with streptokinase and anistreplase). They have also raised a host of issues that require further study. For instance, is there truly a crucial time window for maximum (or for any) benefit? Will aspirin enhance the effects of alteplase as well as the effects of streptokinase? Does the addition of aspirin make the coadministration of heparin superfluous? Is re-exposure to streptokinase within (say) six months truly dangerous or ineffective or both because of residual antibody titres? Is one thrombolytic agent better than another? Has combination thrombolytic therapy anything unique to contribute?

\section{Comparison trials}

Some of these questions may be answered in round two by the direct comparison trials, the first pair of which have recently been published. ${ }^{56}$ In these open trials (the first, GISSI-2, is a large subset trial of the International Study Group) over 20000 patients within six hours of onset of major symptoms were randomised to receive the current standard dose regimens of either streptokinase (1.5 megaunits intravenously over $30-60$ minutes) or alteplase (10 mg intravenous bolus, $50 \mathrm{mg}$ intravenously in the next hour, and $20 \mathrm{mg}$ intravenously in each of the next two hours). All patients were given oral aspirin from admission and half were randomly allocated to receive subcutaneous heparin, 12500 units twice daily, beginning 12 hours after the onset of thrombolysis.

The results at face value provide gratifying reading for health economists-no significant differences for major cardiac clinical events, indices of infarct size, left ventricular function, reinfarction, or death by the end of hospital stay (mean 13 days). There were more strokes with alteplase than with streptokinase $(1.3 \% v 1 \%)$, but more major bleeds with streptokinase than with alteplase $(0.9 \% v 0.6 \%)$ and with heparin $(1 \%)$ versus no heparin $(0.5 \%)$. Heparin did not affect the incidence of stroke or reinfarction.

\section{Is heparin still needed?}

These trials have confirmed both the comparative efficacy and safety of adding oral aspirin to either streptokinase or alteplase. The heparin question, however, may have been confused rather than clarified, because without heparin the in-hospital death rates were streptokinase $9.2 \%$ and alteplase $8 \cdot 7 \%$, whereas with heparin they were streptokinase $\mathbf{7 . 9} \%$ and alteplase $9.2 \%$. The streptokinase results resemble those reported in ISIS-2 where, though heparin was an optional treatment, those patients allocated to streptokinase plus aspirin who were given heparin had a lower death rate than those who were not, albeit at a slightly higher risk of bleeding. In the trial reported by the International Study Group, however, the mortality patterns were already established in the 12 hours before heparin was started, though critics have suggested that the delay before heparinisation disadvantaged the alteplase group because this agent's shorter half life and lower systemic hypocoagulant effect exposed patients in that group to reocclusion. Further, although the dose and mode of heparin administration in the trial reported by the International Study Group were considered to be both safe and efficacious, ${ }^{78}$ other evidence, both clinical and experimental, suggests otherwise. ${ }^{910}$

This concept of post-thrombolytic vulnerability to reocclusion after alteplase without heparin is supported by several clinical patency studies. In TAMI-3 (Thrombolysis in Acute Myocardial Infarction), patients were randomised to alteplase with or without heparin and there was no difference in the early (90 minute) infarct vessel patency $(79 \%)$, but since all the patients subsequently received intravenous heparin the question of further deferment was not addressed." In the heparin and aspirin reperfusion trial, 204 patients received alteplase plus either low dose aspirin $(80 \mathrm{mg})$ or intravenous heparin and the infarct vessel patency rates at 15 hours were $52 \%$ and $82 \%$ respectively. ${ }^{12}$ In a similar but smaller study, Bleich and colleagues reported 55-59 hour patency rates of $44 \%$ with alteplase alone, compared with $71 \%$ when alteplase was coadministered with heparin (5000 unit bolus, then 1000 units per hour intravenously). ${ }^{13}$

The largest study to examine this issue was reported by Professor de Bono for the European Cooperative Study Group at the recent European Congress of Cardiology in Stockholm. Six hundred and fifty two patients with evolving myocardial infarction were randomised double blind to receive alteplase $100 \mathrm{mg}$ plus aspirin plus either immediate intravenous heparin ( 5000 unit bolus followed by 1000 units per hour until angiography) or placebo. Coronary angiography at 48-120 hours (mean 81 hours) showed TIMI (Thrombolysis in Myocardial Infarction) grade 2 or 3 perfusion of $83 \%$ in the heparin group compared with $75 \%$ in the placebo group-a significant but less dramatic difference than in the study reported by Bleich et al. There were no differences in other clinical variables. Finally, the 
random discontinuation of intravenous heparin at 24 hours and its replacement with aspirin plus dipyridamole had no deleterious impact on the pre-discharge rates for coronary artery patency $(79 \%){ }^{14}$

Though comparable studies have not been reported with streptokinase, the message for alteplase seems to be that some form of anticoagulation (not just aspirin) may be essential to maintain the high patency rates. If indeed patency is more quickly achieved with intravenous alteplase than with streptokinase, ${ }^{15}$ and if early patency is advantageous and its effect measurable, then a re-run of the trial reported by the International Study Group but with early heparin should give the answer. However, the other large (more than 40000 patients) round two, trial comparing alteplase, streptokinase, and anistreplase may clarify this issue, though even in this (ISIS-3) trial administration of heparin is deferred for four hours.

\section{Round three studies}

Is it possible and safe to try to exploit the virtues of two (or more) thrombolytic drugs given either together or sequentially-such as an initial high dose alteplase to achieve maximum patency as quickly as possible, ${ }^{16}$ followed by streptokinase or urokinase to maintain systemic hypocoagulation with less clot specificity, which may lessen the haemorrhagic stroke rate. Some clinical data commend this dual approach. The TAMI investigators reported a reocclusion rate as low as $2 \%$ when alteplase was given with urokinase, compared with $12 \%$ for alteplase and $7 \%$ for urokinase alone. ${ }^{17} \mathrm{~A}$ preliminary study to compare the results with alteplase and streptokinase and alteplase alone has reported similar figures. ${ }^{18}$ Initial patency rates do not seem to be greatly improved by dual therapy and in the large mortality trials reocclusion rates of $10-15 \%$ are certainly not clinically recognised as reinfarctions.

The prospect of giving two thrombolytic drugs plus aspirin and simultaneous heparin is awesome, but such trials are planned and pilot studies are in progress. In the mean time we are eager to see whether ISIS-3 delivers a message substantially different from that of the International Study Group and in 1992 we should have the results of LATE (Late Assessment of Thrombolytic Efficacy), which is a double blind study randomising patients at 6-24 hours from the onset of symptoms to either placebo or alteplase; both treatment groups are also being treated with oral aspirin and early heparin.

\section{Re-exposure to streptokinase}

The question of re-exposure to streptokinase hinges on the importance of persisting streptokinase neutralising antibodies. Though the pretreatment titres-presumably residua from previous streptococcal infections-do not seem to correlate with either 90 minute infarct vessel patency or the likelihood of hypotensive reactions after either streptokinase or anistreplase, the titre of antibodies rises rapidly and remains high enough at six months "theoretically" to neutralise half a standard 1.5 megaunit dose of streptokinase or anistreplase. ${ }^{1920}$ Clearly the measurement of pretreatment antibodies is not necessary in patients who have never received streptokinase or anistreplase, nor is it practicable in those who have within, say, the previous 6-12 months.

This is a far from theoretical dilemma because we need to know whether re-exposure to streptokinase at any time is either dangerous or ineffective or both. The often quoted solution to use alteplase if retreatment is necessary conveniently avoids the question. But how to solve it? Would anyone collaborate in a randomised trial of streptokinase or alteplase in patients who have received streptokinase in say, the previous six months? In such a trial various pretreatment antibodies against streptokinase would be measured and because a large enough trial might be impossible coronary artery patency would need to be a surrogate for mortality. Patients would need to be stratified according to time from initial exposure to streptokinase. Without such a trial alteplase will presumably occupy the re-exposure niche. For most other patients, however, the "gold standard" thrombolytic therapy at present remains streptokinase plus aspirin-plus heparin?

Department of Medicine,

R G WILCOX

University Hospital,

Nottingham NG7 2UH

1 Gruppo Italiano per lo Studio della Streptochinasi nell'Infarto Miocardico. Long-term effects of intravenous thrombolysis in acute myocardial infarction: final report of the GISSI study. Lancet 1987;ii:871-4.

2 ISIS-2 (Second International Study of Infarct Survival) Collaborative Group. Randomised trial of intravenous streptokinase, oral aspirin, both, or neither among 17187 cases of suspected acute myocardial infarction. Lancet 1988;ii:349-60.

3 AIMS Trial Study Group. Long-term effects of intravenous anistreplase in acute myocardial infarction: final report of the AIMS study. Lancet 1990;335:427-31

4 Wilcox RG, von der Lippe G, Olsson CG, Jensen G, Skene AM, Hampton JR, for the Anglo-Scandinavian Study of Early Thrombolysis. Effects of alteplase in acute myocardial infarction: 6-month results from the ASSET study. Lancet 1990;335:1175-8.

5 Gruppo Italiano per lo Studio della Streptochinasi nell'Infarto Miocardico. GISSI-2. A factorial randomised trial of alteplase versus streptokinase and heparin versus no heparin among 12490 patients with acute myocardial infarction. Lancet 1990;336:65-71.

6 The International Study Group. In-hospital mortality and clinical course of 20891 patients with suspected acute myocardial infarction randomised between alteplase and streptokinase with or without heparin. Lancet between alteplase

7 The SCATI (Studio sulla Calciparina nell'Angina e nella Trombosi Ventricolare nell'Infarto) Group. Randomised controlled trial of subcutaneous calcium-heparin in acute myocardial infarction. Lancet 1989;ii: $182-6$

8 Bentley PG, Kakkar VV, Scully MF, et al. An objective study of alternative methods of heparin administration. Thromb Res 1980;19:177-87.

9 Hull RD, Raskob GE, Hirsh J, et al. Continuous intravenous heparin compared with intermittent subcutaneous heparin in the initial treatment of proximal-vein thrombosis. N Engl J Med 1986;315:1109-14.

10 Rapold HJ. Promotion of thrombin activity by thrombolytic therapy without simultaneous anticoagulation. Lancet 1990;335:481-2.

11 Topol EJ, George BS, Kereiakes DJ, et al, the TAMI Study Group. A randomised controlled trial of intravenous tissue plasminogen activator and early intravenous heparin in acute myocardial infarction. Circulation 1989;79:281-6.

12 Hsia J, Hamilton WP, Kleiman N, Roberts R, Chaitman BR, Ross AM, for the Heparin-Aspirin Reperfusion Trial (HART) investigators. A comparison between heparin and low-dose aspirin as adjunctive therapy with tissue plasminogen activator for acute myocardial infarction. $N$ Engl J Med
1990;323:1433-7.

13 Bleich SD, Nichols T, Schumacher R, et al. The role of heparin following coronary thrombolysis with tissue plasminogen activator (t-PA) [Abstract]. Circulation 1989;80(suppl II):II-113.

14 National Heart Foundation of Australian Coronary Thrombolysis Group. A $\mathcal{\omega}$ randomised comparison of oral aspirin/dipyridamole versus intravenous $\sigma$ heparin after rtPA for acute myocardial infarction [Abstract]. Circulation 1989;80(suppl II):II-114.

15 Verstraete $M$, Bernard $R$, Rory $M$, et al. Randomised trial of intravenous recombinant tissue-type plasminogen activator versus intravenous $\mathscr{E}$ streptokinase in acute myocardial infarction. Lancet 1985;1:842-7.

16 Neuhaus KL, Feurer N, Jeep-Tebbe S, Niederer $W$, Vogt A, Tebbe U. $\square$ Improved thrombolysis with a modified dose regimen of recombinant $\bar{D}$
tissue-type plasminogen activator. $\mathrm{J} \mathrm{Am}$ Coll Cardiol 1989;14:1566-9.

17 Califf RM, Topol EJ, Harrelson L, et al, the TAMI Study Group. In-hospital clinical outcomes in the TAMI-5 study [Abstract]. J Am Coll Cardiol 1990;15:76A.

18 Grines CL, Nissen SE, Booth DC, et al. The KAMIT Study Group. A prospective randomised trial comparing combination half dose tPA with streptokinase to full dose tPA in acute myocardial infarction: preliminary report [Abstract]. J Am Coll Cardiol 1990;15:4A

19 Gemmill JD, Hogg KJ, Burns JMA, et al. Lack of relation of pretreatment

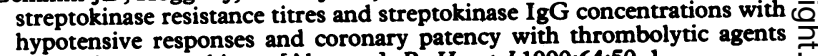
containing streptokinase [Abstract]. Br Heart J 1990;64:50-1.

20 Jalihal S, Morris GK. Antistreptokinase titres after intravenous streptokinase. Lancet 1990;335:184-5.

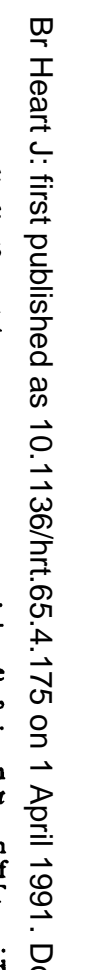

